\title{
Risk management considerate kinetic of the subsidence on top of closed room and pillar mines
}

\author{
T Delaunay GEODERIS, Francef \\ R Hadadou GEODERIS, France \\ H Baroudi INERIS, France \\ JP Josien Rovconsult, GD of Luxembourg \\ JP Piguet Lorraine University - Georessources LAB, France
}

\begin{abstract}
Since the 20th century, many progressive subsidences have occurred in France over former operated and abandoned room and pillar mines. Some of them have had a profound impact on buildings, requiring the evacuation of people. Among the events recorded, it was found that some subsidences set in quickly (a few days at most) and others in a slow manner (several weeks or months). In a risk prevention approach led by the French administration and at the initiative of the Public Institution GEODERIS, the authors embarked on a study of the kinetics of subsidence on the basis of reports from the best documented occurrences. $A$ methodology has been developed so that, based on readily available data, the time required to achieve structural damage to buildings during mine subsidence can be estimated. The simple-to-use model obtained can potentially be a tool for risk prevention.
\end{abstract}

Keywords: mine, subsidence, kinetic, risk

\section{$1 \quad$ Introduction}

As part of the prevention of risks related to abandoned mining operations managed by the French administration, studies were entrusted to the Public Institution GEODERIS, which was facilitated by a group of experts. Methodologies have thus been developed to determine areas of potential hazards and risks, and in particular to identify areas of progressive subsidence risk over former abandoned room and pillar mines. Indeed, during the 20th century and even today, many subsidences occurred in France in this context. About a hundred events have been recorded over old iron, bauxite or asphalt limestone mines. Among these events, 70 involved the mining operations of the Lorrain Iron Basin (LIB), some of which caused major damage to buildings and necessitated the evacuation of people. However, it has been observed in this Lorraine basin that some subsidences are quickly implemented (one day for the subsidence of Auboué in 1996 or Moutiers in 1997) and others in a slow way (six months for the subsidence of Roncourt in 1999 or 4 years for the subsidence of Angevillers in 2009).

For this reason, research has been initiated on the kinetics of subsidence in order to improve risk prevention. The objective is to find, on a potentially unstable mine, a relationship between the mining and geological data of this operation (extraction ratio, opening, depth, mechanical stress) available from the mine plans and the time required to place the subsidence on the surface in the event of pillar failure.

The approach involved establishing these relationships based on the feedback from 9 well documented events of surface subsidence measurements. This method was then used to evaluate about thirty cases of subsidence that had not been measured but whose kinetics had been established.

Once validated, the method can be applied to attempt to predict the kinetics of a potential subsidence on identified risk areas, thus improving public safety. 


\section{Methodology}

\subsection{Sensitivity to surface subsidence}

A subsidence results in the formation of a surface trough, particularly characterized by its maximum amplitude $\mathrm{Am}$ and a maximum slope $\mathrm{Pm}$ at the point of inflection of the trough (Figure 1). Effects on buildings are determined by the slope and the horizontal strain from the ground (Proust 1964). The maximum values are proportional to the ratio between $\mathrm{Am}$ and the depth $\mathrm{H}$ of the failed operation that causes the subsidence. At the same depth and width of an abandoned mine, it is necessary that Am is sufficiently "large" for Pm to reach values that produce perceptible surface effects.

Studies on the vulnerability of buildings have shown that the first structural damage to a traditional French building appears with a minimum slope value of $1.5 \%$ (Pham \& Chenaf 2015). The critical amplitude Ac of the subsidence corresponds to the value when this gradient reaches a point when Pm equals $1.5 \%$. Ac is therefore expressed by a relationship that is only a function of the depth $\mathrm{H}$ of the operation.

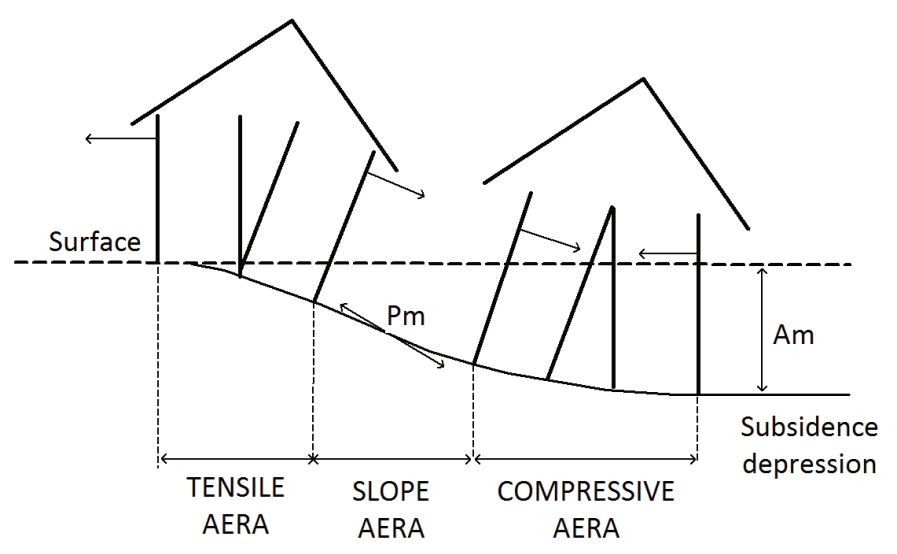

\section{Figure 1 Building impacts along the border of a subsidence trough}

The studies conducted in LIB, who the overburden is constant and composed of stiff limestones. Based on measurements from all subsidences in the LIB, the following average empirical relationships were established:

$$
A m=a W \tau
$$

Where:

$$
\begin{array}{ll}
a= & 0.5(\text { in LIB }) \\
W= & \text { exploited opening } \\
\tau= & \text { extraction ratio }
\end{array}
$$

$$
\mathrm{Pm}=\mathrm{bAm} / \mathrm{H}
$$

Where:

$$
\begin{aligned}
& \mathrm{b}=\quad 5 \text { (in LIB) } \\
& \mathrm{H}=\quad \text { depth }
\end{aligned}
$$

As a result for $\mathrm{Pm}=1.5 \%$ :

$$
\begin{gathered}
A C=(1.5 \mathrm{H} / 100) / 5 \\
A C=0.003 \mathrm{H}
\end{gathered}
$$


The critical time Tc, expressed in days, is defined as the time required for the subsidence process to generate the first structural damage on buildings. It is obtained when at least one point of the surface is sloping at $1.5 \%$. In our predictive analysis, it is agreed that a subsidence will be considered as "rapid" if Tc is less than a week ( 8 days). This value, defined in agreement with the French administration, corresponds to the estimated time needed to implement the evacuation of people.

To characterize the ability of subsidence to produce effects that could affect the stability of buildings, an index $D$ was introduced. $D$ is defined as the ratio between $A c$ and $A m$ and is consequently between 0 and 1 . This index $\mathrm{D}$ depends only on the operating parameters: depth $\mathrm{H}$, opening $\mathrm{W}$ and deflection rate $\tau$ When Ac, calculated according to equation (3), is greater than Am, it means that the critical subsidence is never reached and that the risk to the safety of persons must be considered as zero.

\subsection{Geometric progression of a subsidence}

The fracture process within mining-works, made up of a group of adjacent pillars, will commence at a point where the security factor is at its weakest, either due to a higher level of stress with the presence of a stacking edge or by a lower level of pillar resistance (brittle pillar fractures). The floor kinetics is the progression of the rupture from one pillar to the next (Figure 2).

During a progressive subsidence, the surface trough widens and deepens as the collapse of the pillars at the bottom progresses. The maximum amplitude of subsidence Am at any given time is related to the width $\mathrm{L}$ of the collapsed mine. In LIB, the first signs appear on the surface for a broken zone width of $0.4 \mathrm{H}$ (Al Heib et al 2003). The most significant effects are only felt when it reaches $0.8 \mathrm{H}$. The maximum amplitude of the subsidence Am is reached when the collapsed surface is equal to the depth. The evolution of the amplitude of the subsidence $A$ in the centre of the trough is expressed by a subsidence curve called "S" (Figure 3 ).

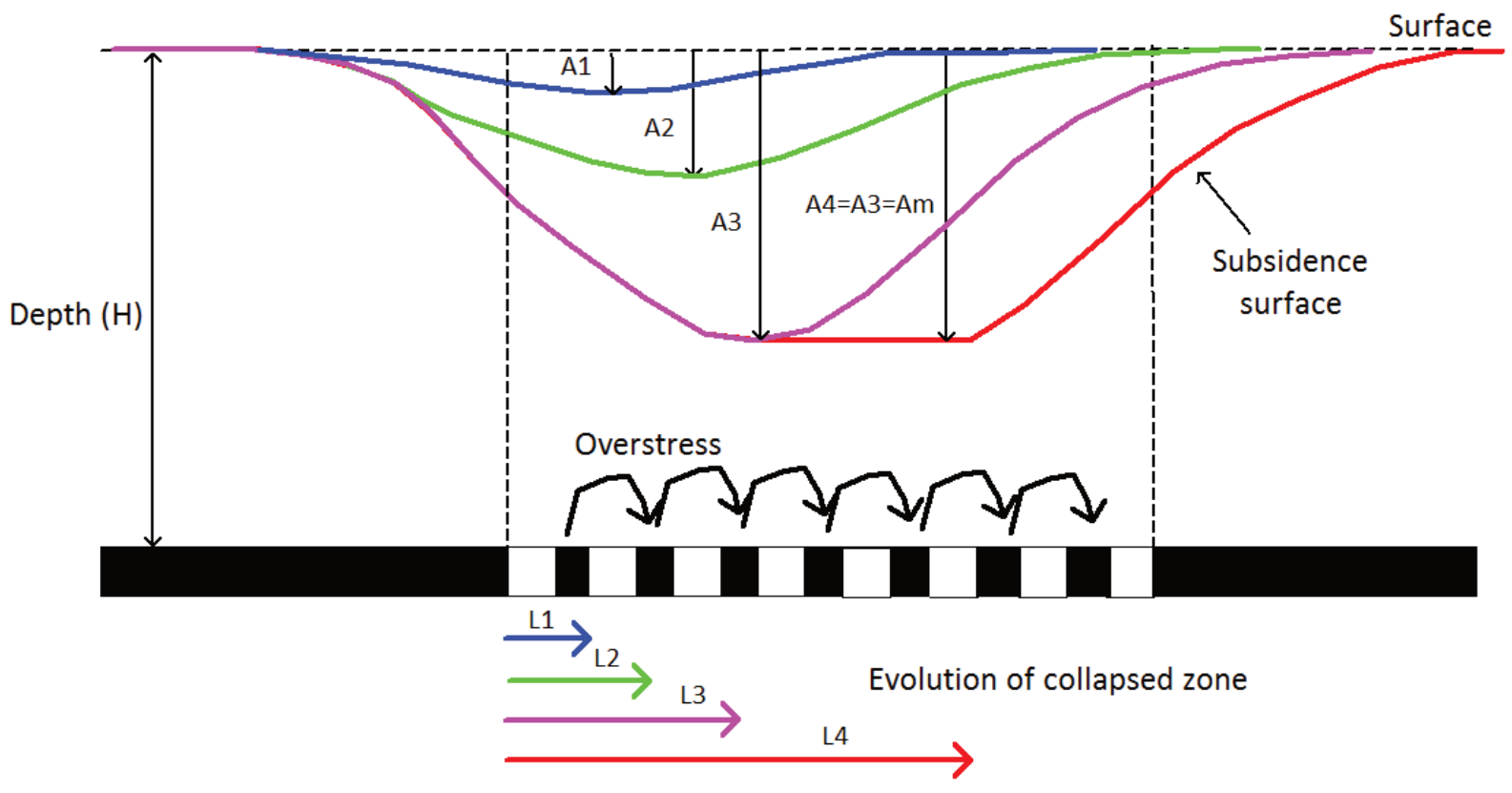

Figure 2 Progression of the subsidence surface trough according to the progression of the collapse of the mine 


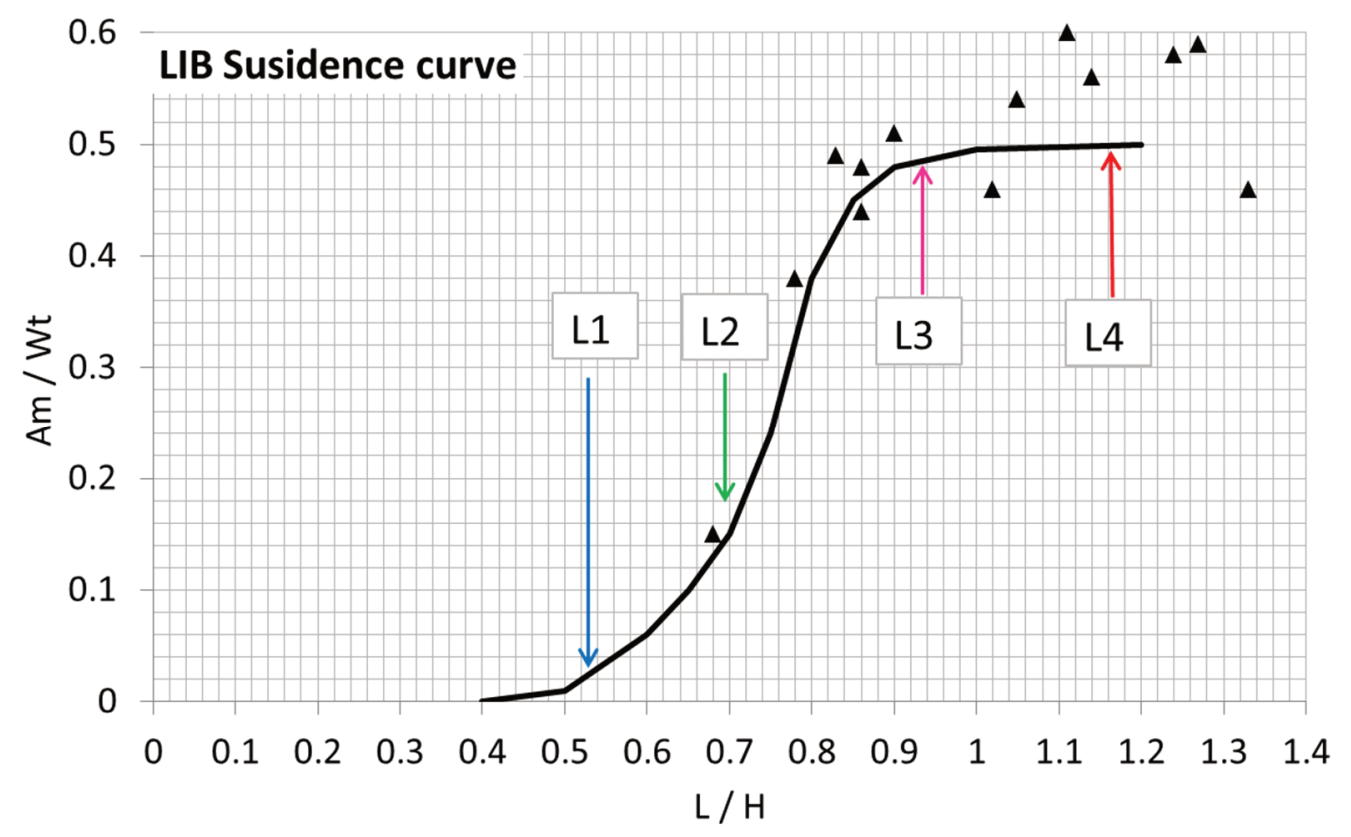

Figure 3 Curve of the subsidence evolution according to the collapsed width below. Lorrain Iron Basin (LIB) case

The kinetics of the phenomenon is reflected, at a given point on the surface, by a vertical displacement curve as a function of time (Figure 4). The evolution of its derivative with respect to time, i. e. the steepness of this curve, can be represented by a characteristic time $v$ necessary for half of the maximum amplitude of subsidence to be reached at the centre of the trough ( $\mathrm{Am} / 2$ ). The critical time Tc will be shorter if the subsidence curve as a function of time is steeper.

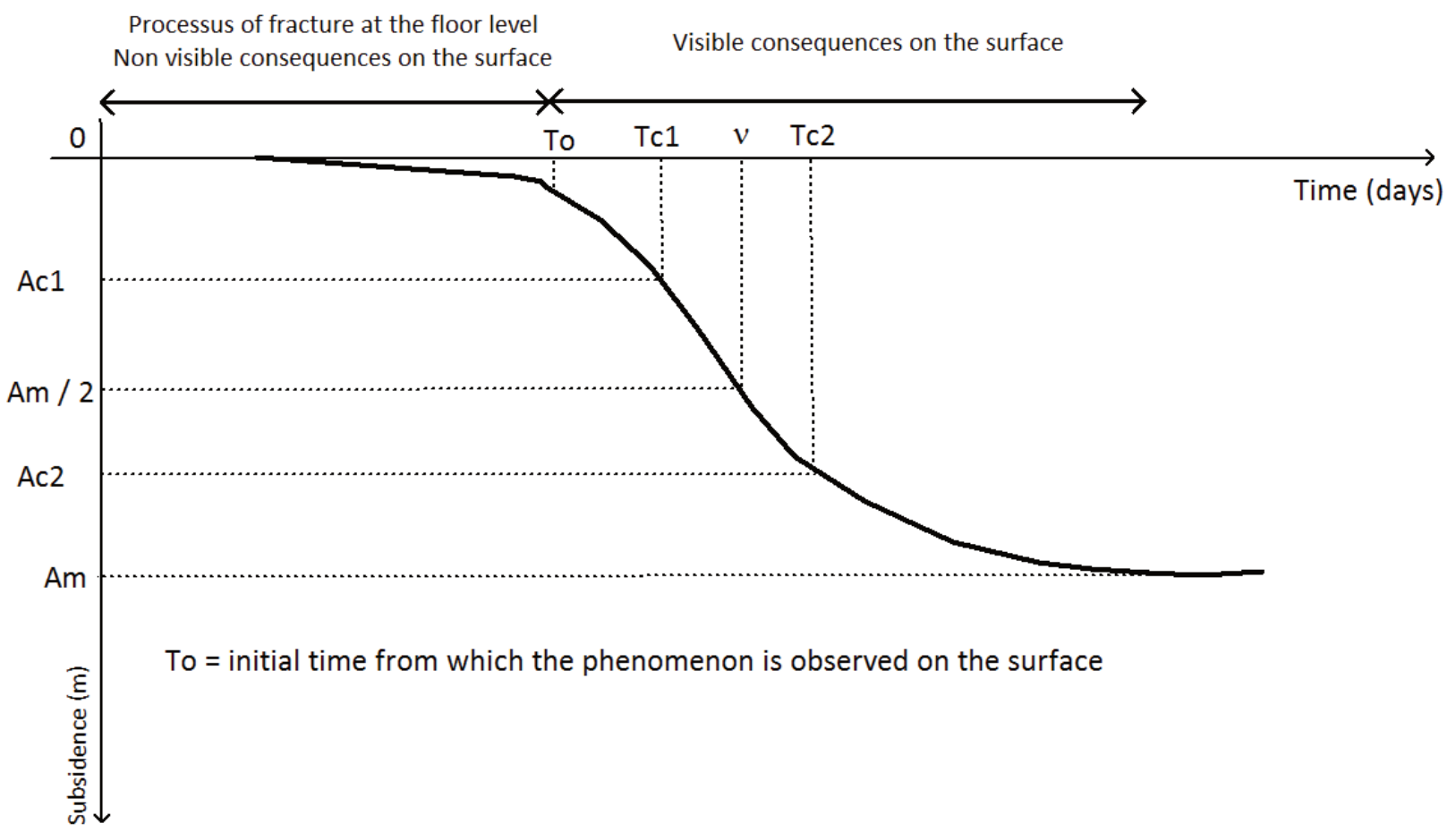

Figure 4 Evolution in function of the time taken to reach the amplitude of collapse at a particular point of the Lorraine Iron Basin (LIB) 
Tc depends on the relative values of $A c$ and $A m$ and therefore on the $D$ index. If $A c$ is small compared to Am, the surface disorders will appear at the beginning of phase 2 of the curve. On the other hand, if Ac is close to Am, they will only occur during the residual collapse phase or never if Ac is greater than Am. An expression of Tc as a function of $D$ was chosen to represent the progression of Tc to infinity as $D$ approaches 1:

$$
\mathrm{Tc}=\mathrm{v}(\mathrm{D} / 1-\mathrm{D})
$$

For a $\mathrm{D}$ ratio equal to 0.5 , we find Tc equal to $v$, which corresponds to the definition of the characteristic time $v$.

\section{Retro-analysis of measurement events}

In order to verify the proposed model, a sample of 9 progressive subsidences, well documented and with dated amplitude measurements were retained. To be statistically representative, these 9 events present the widest possible range of operating characteristics and measured values (subsidence parameters and characteristic times) (table 1).

Table 1 Mining and measured Kinetic characteristics of the studied events

\begin{tabular}{|c|c|c|c|c|c|c|c|c|c|c|c|}
\hline \multirow{2}{*}{$\begin{array}{l}\text { Name of the } \\
\text { event } \\
\text { Mou_1997 }\end{array}$} & \multirow{2}{*}{$\begin{array}{l}W \\
\text { (m) }\end{array}$} & \multirow{2}{*}{$\begin{array}{l}\begin{array}{l}\text { Gallery } \\
\text { width } \\
\text { (m) }\end{array} \\
6\end{array}$} & \multirow{2}{*}{$\begin{array}{l}\begin{array}{l}\text { Pillar } \\
\text { width- } \\
\text { Ip (m) }\end{array} \\
12\end{array}$} & \multirow{2}{*}{$\begin{array}{l}\begin{array}{l}\text { Pillar } \\
\text { length- } \\
\text { Lp (m) }\end{array} \\
12\end{array}$} & \multirow{2}{*}{$\begin{array}{l}\begin{array}{l}\text { Depth } \\
\text { (H) }\end{array} \\
120\end{array}$} & \multicolumn{3}{|c|}{$v$ (days) Am (m)D } & \multirow{2}{*}{$\begin{array}{l}\begin{array}{l}\mathrm{T} \mathrm{C}_{\text {measured }} \\
\text { (days) }\end{array} \\
1\end{array}$} & \multirow{2}{*}{$\begin{array}{l}\begin{array}{l}\text { Tc calculated } \\
\text { (days) }\end{array} \\
1\end{array}$} & \multirow{2}{*}{$\begin{array}{l}\text { Kinetic } \\
\text { level } \\
\text { with Tc }\end{array}$} \\
\hline & & & & & & 1 & 0.97 & 0.28 & & & \\
\hline Aub_96 & 5.0 & 6 & 12 & 14 & 170 & 2 & 1.33 & 0.43 & 1 & 2 & Rapid \\
\hline Affl_01 & 7.0 & 6 & 24 & 24 & 255 & 2 & 1.26 & 0.96 & 64 & 48 & Slow \\
\hline Doma_01 & 5.0 & 6 & 27 & 27 & 245 & 3 & 0.83 & 1.14 & Infinite & 0 & Slow \\
\hline Cru_1977 & 3.8 & 6 & 11 & 25 & 180 & 2 & 0.91 & 0.79 & 26 & 8 & Slow \\
\hline Dante_1997 & 5.0 & 8 & 12 & 49 & 170 & 41 & 1.21 & 0.78 & 45 & 145 & Slow \\
\hline Roc_2008 & 3.0 & 3 & 10 & 37 & 190 & 108 & 0.43 & 2.71 & Infinite & $<0$ & Slow \\
\hline Ron_1999 & 2.5 & 6 & 6 & 85 & 140 & 100 & 0.67 & 0.57 & 103 & 133 & Slow \\
\hline Ang_2009 & 5.0 & 6 & 11 & 40 & 175 & 36 & 1.09 & 0.78 & 460 & 128 & Slow \\
\hline
\end{tabular}

There is a large variability in the measured Tc values, from 1 day for the fastest events to 460 days for the slowest. The Doma_01 and Roc_2008 events have a value of D greater than 1, which means that Ac, and thus Tc, will never be obtained. In both cases, Tc is then defined as "Infinite". The classification between "rapid" (Tc < 8 days) and "slow" events is confirmed by the calculations. Nevertheless, significant differences between the measured and calculated values are observed for some "slow" events, particularly for the Ang_2009 event. We will later observe that these differences are related to a particular kinetic of the events in question (slowing down or implementation of subsidence in several phases).

The graph below illustrates the subsidence curves established according to the amplitude of subsidence measurements performed during events. Doma_01 and Roc_2008 events are distinguished by the profile of subsidence curves. Doma_01 shows several bearings (or plateaus) reflecting alternating phases of more or less long stops and sometimes rapid resumption of subsidence. Note that these Doma_01 and Roc 2008 events did not reach the critical amplitude Ac.

For Mou_1997, Aub_96, Cru_1977 and Affl_01 (group 1), the time (v) ranges from one to three days. The subsidence curve obtained is very steep during the acceleration phase and is therefore a characteristic of fast kinetics. Profiles of the subsidence curves of Dante_1997, Ron_1999 and Ang_2009 (group 2) cases 
differ from the theoretical "S" profile used in the model. They appear less steep, have small bearings, which ultimately translates into a slower kinetics.

It can also be observed that Tc can be variable within the same group. In group 1, under fast kinetics, Tc is 1 day for Mou_1997 and Aub_96 and 26 and 45 days for Cru_1977 and Affl_01 events. This is directly related to the ratio $D$. In the first cases, Ac is achieved before half of $A m$ is obtained $(D<0.5)$. In the second cases, Ac is close to Am (D>0.75). Tc is then only attained during the subsidence stabilisation phase.

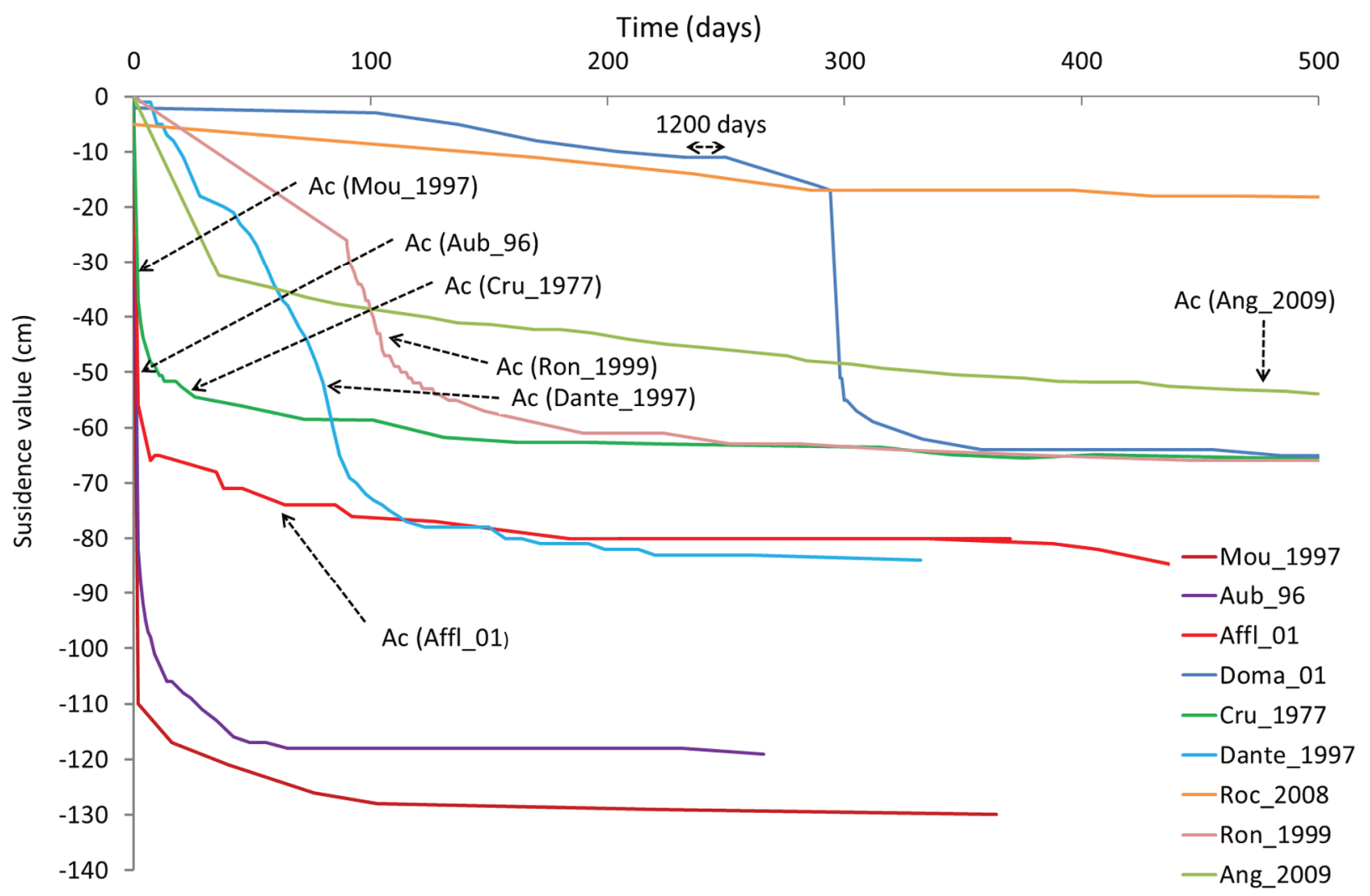

Figure 5 Subsidence curves of the 9 events obtained from the measured amplitudes

These observations confirm the relationship between kinetics and the critical amplitude of a subsidence to determine the critical time of its implementation. In contrast, in a predictive approach, the only data available are the operating parameters from mine plans. The estimation of kinetics, Ac and Tc, can only be carried out on the basis of relationships that link these different parameters to time.

\section{Estimate of critical time}

\subsection{Estimate of the kinetics of a subsidence}

In 2015, it was established that at high stress and equal pillar surface area, the geometry of the pillars plays an essential role in their failure kinetics (Hosni \& Hadadou 2015). Due to the geological nature of constant overburden over a given basin, the implementation of surface subsidence will be faster if the progression of the ruin concerns square pillars, and slower if the pillars are long. With equal pillar geometry and surface area, it will also be faster if the slenderness of the pillars is high. These influences were reflected in a kinetic index Ic as a function of a shape index of pillars If and the inverse of their slenderness according to:

$$
\mathrm{Ic}=\mathrm{If}(\mathrm{VSp} / \mathrm{W})
$$


Where:

$$
\text { If }=\text { ratio between the hydraulic diameter of the pillar and its width.5 (in LIB) }
$$

For a rectangular pillar with a surface area of $S p$, a perimeter of $P$, a length of $L p$ and a width of $I p$, we find:

$$
\begin{gathered}
\text { If }=4 S p / P \\
\text { If }=2 L p /(I p+L p)
\end{gathered}
$$

After calculating the kinetic indices of the 9 reference events presented above (Table 2), a projection in the plan (Ic, v) is made (Figure 5). The graph illustrates that time $v$ increases with Ic. To estimate $v$, and therefore the steepness of the curve of a potential subsidence, a linear relationship has been established between $v$ and Ic as follows:

$$
\begin{gathered}
v=1 \text { for } \mathrm{Ic}<4 \\
v=9 \mathrm{Ic}-35 \text { for } \mathrm{Ic}>4
\end{gathered}
$$

\begin{tabular}{|c|c|c|c|c|c|c|c|}
\hline $\begin{array}{l}\text { Name of the } \\
\text { event }\end{array}$ & $\begin{array}{l}\text { Form } \\
\text { index-If }\end{array}$ & $\begin{array}{c}\text { kinetic } \\
\text { index-lc }\end{array}$ & $\begin{array}{l}\text { Time } v_{\text {estimated }} \\
\text { (days) }\end{array}$ & Am estimated & Destimated $_{\text {f }}$ & $\begin{array}{l}\text { Tc estimated } \\
\text { (days) }\end{array}$ & $\begin{array}{l}\text { Kinetic level } \\
\text { with } T_{\text {cestimated }}\end{array}$ \\
\hline Mou_1997 & 1.00 & 3.43 & 1 & 0.98 & 0.37 & 1 & Rapid \\
\hline Aub_96 & 1.08 & 2.79 & 1 & 1.33 & 0.39 & 1 & Rapid \\
\hline Affl_01 & 1.00 & 3.43 & 1 & 1.26 & 0.61 & 2 & Rapid \\
\hline Doma_01 & 1.00 & 5.40 & 14 & 0.83 & 0.89 & 113 & Slow \\
\hline Cru_1977 & 1.39 & 6.06 & 20 & 0.91 & 0.59 & 28 & Slow \\
\hline Dante_1997 & 1.61 & 7.79 & 34 & 1.21 & 0.42 & 28 & Slow \\
\hline Roc_2008 & 1.57 & 10.1 & 56 & 0.43 & 1.30 & 22 & Slow \\
\hline Ron_1999 & 1.87 & 16.9 & 117 & 0.67 & 0.64 & 200 & Slow \\
\hline Ang_2009 & 1.57 & 6.58 & 24 & 1.09 & 0.48 & 26 & Slow \\
\hline
\end{tabular}

Table 2 Kinetic estimated characteristics of the studied events

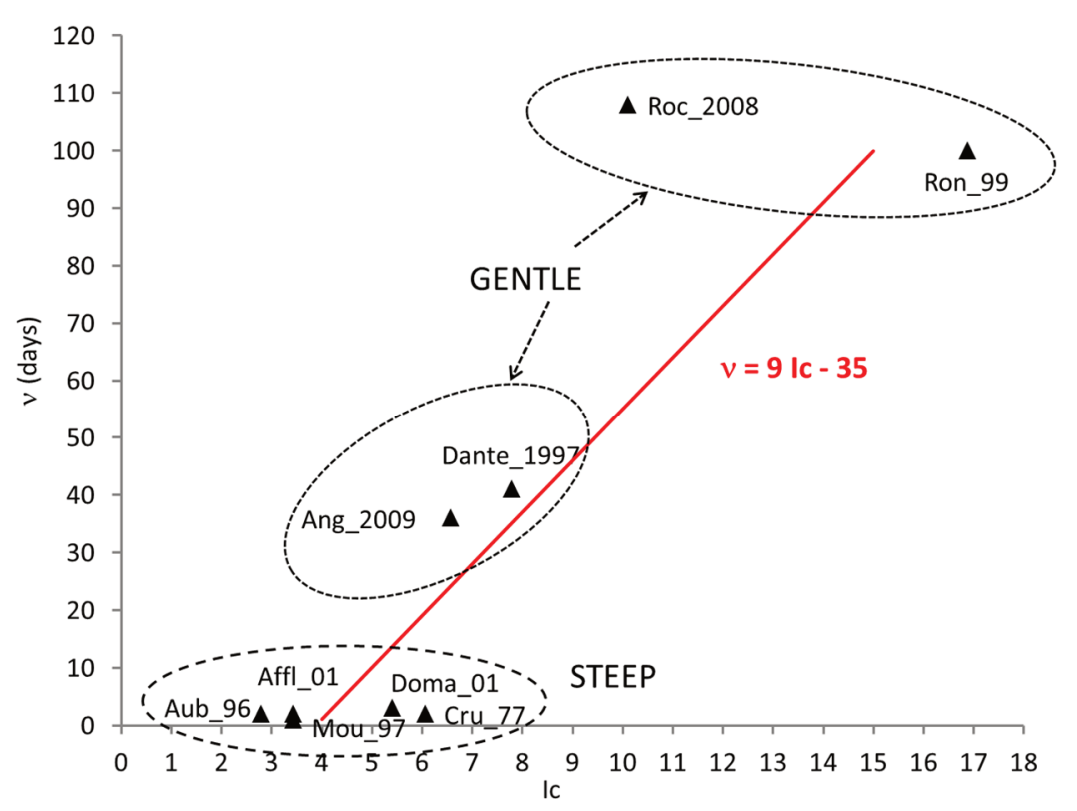

Figure 6 Projection of the 9 events in the plan (IC, v) 
Concerning time $v$, it is observed that the Doma_01 and Cru_1977 events have a difference between the measured and estimated values sufficient for the theoretical stiffness of the subsidence curve to be significantly lower. For example, for the event Doma_01 which occurred in two bearings (Figure 4), $v$ has been measured on the second bearing and does not take into account the delay in starting (1200 days) that the time $v$, evaluated by the relationships dependent on the operating geometry, cannot predict.

According to the calculated kinetic indices, we find the two groups of events distinguished by the measured time $v$ (Figure 6). The "bearing" kinetics of Group 2 events during the main subsidence phase (Phase 2) is related to the local increase in the size of the pillars, which slows down or temporarily stops the progression of their failure.

\subsection{Estimate of the $D$ index}

It should be recalled that index $D$ has been defined as the ratio between the amplitude of the critical subsidence $A c$ and the maximum amplitude Am where Ac is calculated for a subsidence slope equal to $1.5 \%$ and obtained by equation (4).

The values of the ratios Dmeasured and Destimated were compared (Figure 7). The largest difference is obtained by the Roc_2008 event for which the ratio D drops from 2.71 to 1.3. The value of Destimated however remains higher than 1 which corresponds to the failure to reach Ac (and Tc) and thus confirms the retro-analysis of this event. With the exception of Mou_1997 and Ron_1999, the observed D values for other events are higher than those estimated as explained by the overestimation of Am calculated from measurements on mining plans. This development is in line with safety.

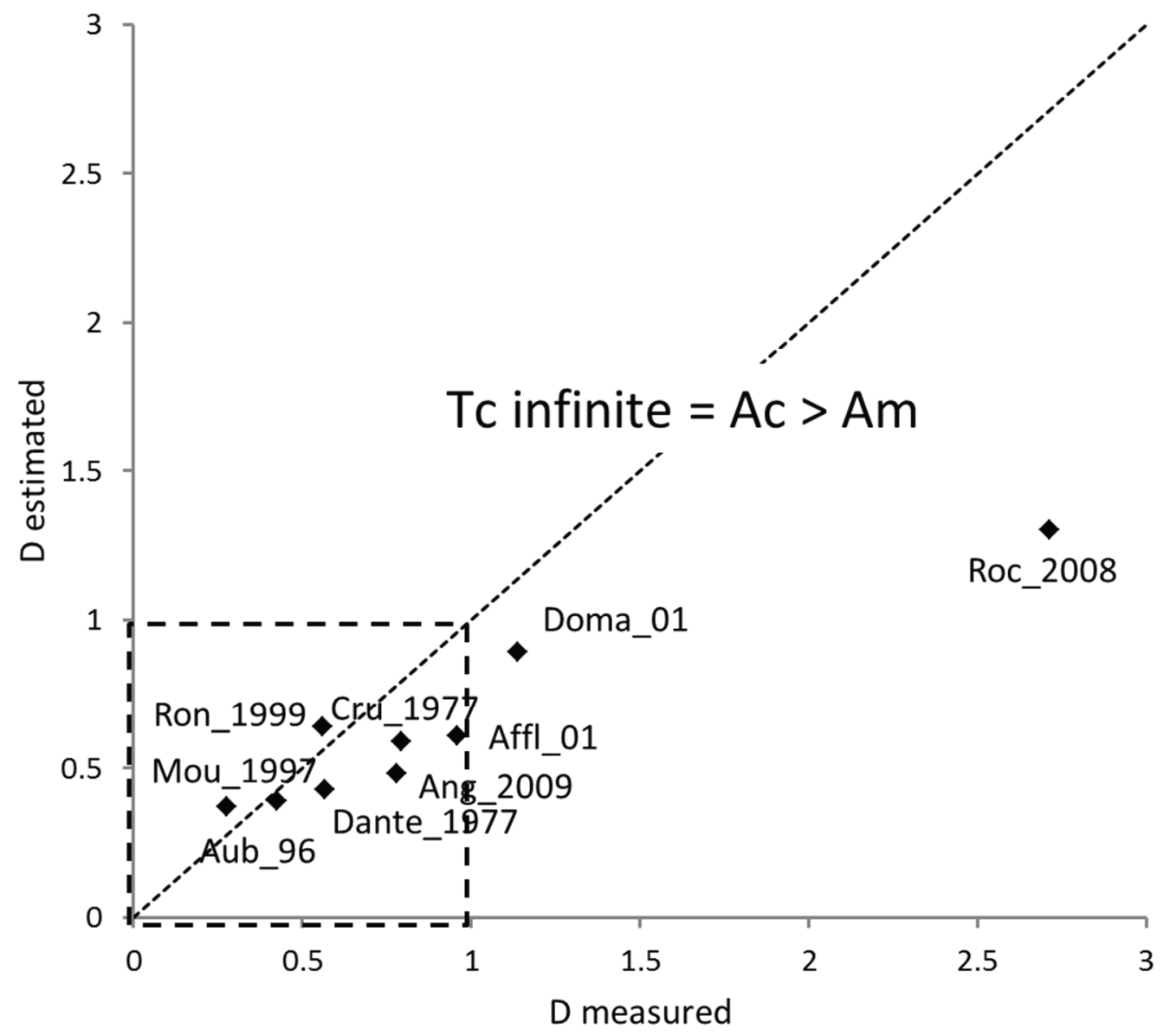

Figure 7 Projection of the 9 events in the plan ( $\left.D_{\text {measured }}, D_{\text {estimated }}\right)$ 


\subsection{Estimate of critical time}

In a forward-looking approach, it should be recalled that the limit between a subsidence defined as "rapid" (potentially risky for public safety) and "slow" is set at one week (8 days).

The established relationship Tc as a function of $D$ results in an acceleration of the time increase when $A c$ approaches $\mathrm{Am}(\mathrm{Ac}>0.8 \mathrm{Am})$ and significantly influences the estimated value of $\mathrm{Tc}$ in this interval. The critical time estimates Tc are generally in line with the observations, although some values show significant differences with the measured Tc, especially for the Affl_01 and Ang_2009 cases (Figure 8). The poor predictive ranking of the event Affl_01, considered as fast (Tcestimated of 2 days) whereas the observation shows that it was slow (Tcmeasured of 64 days) can be explained by an overestimation of mining exploitation parameters (size of weaker pillars in the plans than in reality) on which the $D$ index depends. For the same reason, the Ang_2009 event, although already classified as slow by the predictive model (Tcestimated $=22$ days), was actually considerably slower (460 days). For these two events (Ang_2009 and Affl_01), the stop or slowdown in the development of subsidence, which cannot be predicted during the examination of the plans, explains why the observed value of Tc is higher than expected. In any case, critical times Tc estimated by this relationship are in the direction of safety.

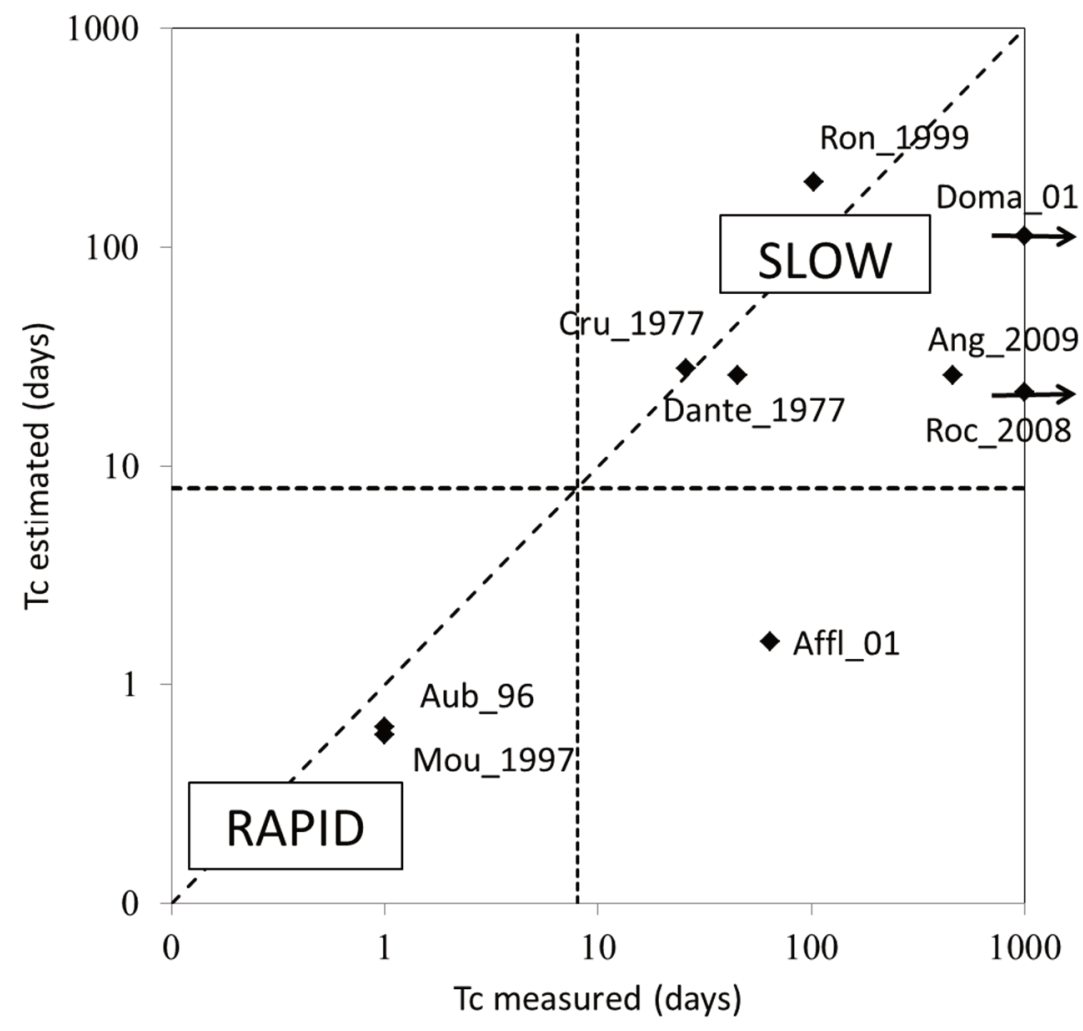

Figure 8 Projection of the 9 events in the plan ( $\left.T c_{\text {measured, }} T C_{\text {estimated }}\right)$

\section{Discussion}

In order to verify the reliability of this model, estimated Tc calculations were performed on the other listed events. Of 70 events listed, the Tc values of 65 events are distributed between 8 days and one year (Figure 9). The proportion of events estimated as rapid (Tc $<8$ days) was $44 \% .5$ events have a Tc defined as "infinite", because Ac is greater than Am.

The circumstances of each event could only be characterised qualitatively due to the absence of accurate subsidence measurements. As a result of descriptions found in the historical archives for 26 events, we have a total of 35 events with the 9 cases in the retro-analysis sample. 
Several failure situations are highlighted. Among events with an estimated critical time Tc greater than 1 month, there are 13 collapses of old abandoned infrastructure roads between caves whose surface subsidence was only detected by analysis of aerial photos. 2 events in the Tc between 8 days and one month correspond to the collapse of panels located at a depth of $200 \mathrm{~m}$ whose progress has been monitored at the bottom. With the velocity of the collapse being $10 \mathrm{~m}$ per day, it took more than 8 days for the collapsed width to evolve from $0.4 \mathrm{H}$ (appearance of the first effects on the surface) to $0.8 \mathrm{H}$ producing sufficient subsidence on the surface. 1-day Tc were calculated for 7 cases of sudden collapse. These particular events are characterized by the extremely rapid occurrence of a surface collapse accompanied by a seismic tremor. In the same way, 3 cases of sudden collapse of panels at the bottom were characterized as rapid ( $T c=1$ day), although they did not produce the same effects on the surface given their small size.

Only one case appears to be incorrectly classified by the Tc parameter. For this event, the estimate of Tc is 1 day while the effects observed at the surface developed slowly. In this case, a layer had previously been struck by lightning a few metres above the collapsed mine. This lightning strike modified the behaviour of the cover and in particular the characteristics of the collapsing trough.

In conclusion, of the 35 documented events, only 2 would have been misclassified based on Tc estimates. The event Affl_01 of the retro-analysis sample and the case described above relating to a collapse of a mine under block caving mine. In these 2 cases, the classification was estimated as rapid (Tc $<8$ days) despite the fact that they were slow, which is in line with safety.

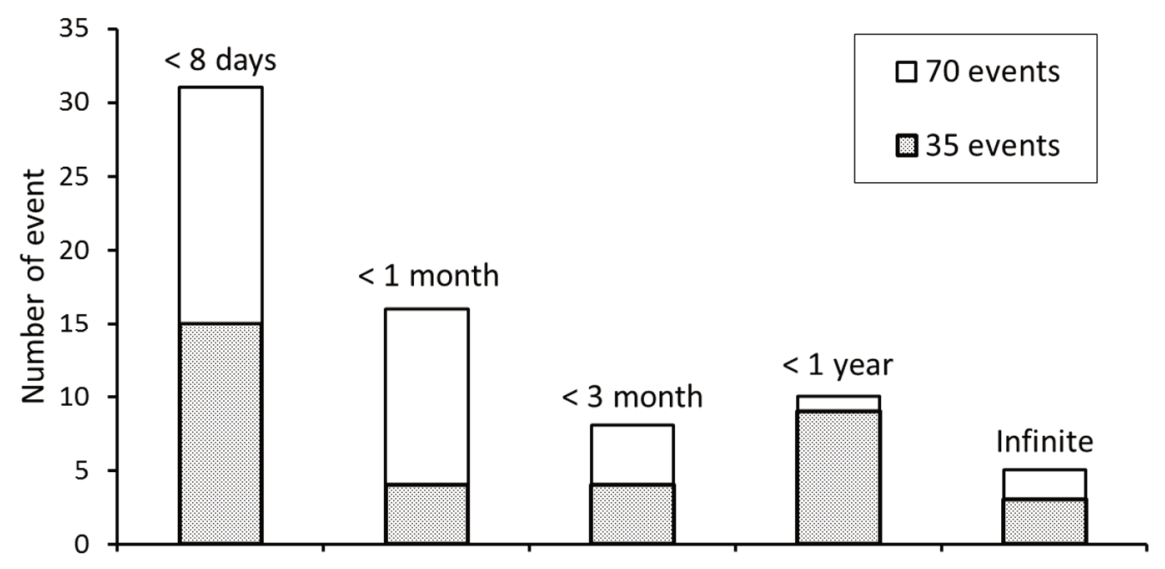

Estimated critical time of subsidence (Tc)

\section{Figure 9 Distribution of the 35 events according to the estimated critical time}

\section{Conclusion}

The critical time Tc for setting up a progressive subsidence has been defined as the time necessary to reach the $1.5 \%$ slope, the minimum value used to generate the first structural damage to buildings.

Retro analysis carried out on 9 progressive subsidences that have occurred over the past 40 years in the LIB has shown that the time it takes to set up a subsidence on the surface can be quite variable, from 1 day to several months. It is determined by the final value of the amplitude of the subsidence and the rate at which it develops.

Analysis of the kinetics of the subsidence curve according to time $v$ conducted on the basis of the subsidence measurements available for the 9 events has shown that it is directly related to the increase in the number of incidents of the failure of pillars in the exploited panel. For equal stress, this progression is accelerated as the pillars tend to be square in shape and of short length relative to their height (small and slender pillar). This characteristic has been quantified by a kinetic index Ic which is the result of the combination of the shape and mass of the pillars. For Ic greater than 4 , the time $v$ increases with Ic and is denoted by the expression $v=9 \mathrm{lc}-35$. When Ic is less than 4 , this time is set at 1 day. 
In a predictive approach, it is necessary to estimate the critical time Tc. Its association with time $v$ is established by the introduction of the $D$ index obtained by the ratio between the amplitude of the critical subsidence Ac and the maximum expected subsidence Am. Ac has been defined as the amplitude of a subsidence required to reach a slope of $1.5 \%$. This amplitude, which depends solely on the depth of the operation, is defined by: $A c=0.003 \mathrm{H}$. The expression of $\mathrm{Tc}$ as a function of $\mathrm{v}$ and $\mathrm{D}$ was chosen to represent the movement of Tc towards infinity when $D$ approaches 1 . In a risk prevention approach, events will then be classified into rapid or slow events according to the value of the time Tc required to implement public safety measures.

The findings from the retro-analysis of historical events have led to the establishment of relationships that make it possible to estimate the kinetics of setting up a progressive subsidence, the parameters of which can be obtained from the operating plans. These simple-to-use connections can potentially be a tool for risk prevention. Discussions are ongoing to adapt these relationships to other forms of pillars and more complex types of operations.

Connections have been established in the case of LIB. While the approach can be generalized to other abandoned room and pillar mines, the parameters of the established links should be adapted to the connections between surface subsidence and the characteristics of mining operations in these deposits.

\section{References}

Hosni, A \& Hadadou, R 2015, Analyses of subsidence kinetics above room and pillar mines and development of kinetic criterion bases on back-analyses subsidence cases, IRSM Congress 2015 Proceedings - International Symposium on Rock Mechanics. Montreal

Al Heib, M, Josien, JP \& El Shayeb. Y 2003. Paramètres d'affaissement pour la hiérarchisation des zones à risque dans le bassin ferrifère lorrain. Post mining International Congress, 2003, Nancy,

https://www.semanticscholar.org/paper/Param\%C3\%A8tres-d'affaissement-pour-la-hierarchisation-\%C3\%A0-HeibJosien/5af4fcc39ff61bfdd9a57a55e9b8e37d7f8f71b3

National Coal Bord 1975, Subsidence engineer's handbook. National Coal Board, Mining Department, London, 111 Pages

Pham DT \& Chenaf, M 2015, Effets des affaissements miniers sur la bâti existant du bassin ferrifère nord-lorrain, vis-à-vis de la sécurité des personnes Centre Scientifique et Technique du Bâtiment, Report $n^{\circ} 26052023$, France.

Proust, A 1964, Etude sur les affaissements miniers dans le Bassin du Nord et du Pas-de-Calais. Revue de l'Industrie Minérale, vol. $46, n^{\circ} 7$ 